\title{
Application of Confocal Laser Scanning Microscopy to the In-situ and Ex-situ Study of Corrosion Processes
}

\author{
Rafael Leiva-García, José García-Antón and Ma José Muñoz-Portero \\ Univ. Politécnica de Valencia, Ingeniería Electroquímica y Corrosión (IEC), \\ Departamento de Ingeniería Química y Nuclear \\ Spain
}

\section{Introduction}

\subsection{Background of confocal microscopy}

In 1955 Marvin Minsky developed the basic concept of confocal microscope when he was a Junior Fellow at Harvard University (Minsky, 1957). The principle of confocal microscopy is based on the rejection of the light from the planes out of focus. Minsky's design performs a point-by-point image construction by focusing a point of light sequentially across a specimen and then collecting some of the returning rays. In this way, Minsky avoided most of the undesirable scattered light that obscures an image if the entire specimen is illuminated at the same time. In addition, the light that the specimen returns passes through a second pinhole aperture that rejects rays that are out of the focal point. The remaining selected light rays are then collected by a photomultiplier and the image is gradually reconstructed using a long-persistence screen. A real image was not formed in Minsky's original microscope; the output from the photodetector was translated into an image of the region of interest. In Minsky's original design the image was built up on the screen of a military surplus long persistence oscilloscope with no facility for hard copy. Minsky said later that the image quality in his microscope was not very impressive due to the quality of the oscilloscope display and not due to lack of resolution achieved with the microscope itself (Minsky, 1988).

To obtain the image, Minsky scanned the specimen by moving the stage rather than the light rays. Using a $60 \mathrm{~Hz}$ solenoid to move the platform vertically and a lower-frequency solenoid to move it horizontally, Minsky obtained a frame rate around one image every $10 \mathrm{sec}$. Fig. 1 shows a scheme of Minsky's invention.

Although Minsky built his microscope with two objective lenses he realized that the system could work using a single objective lens operated in a reflected light mode. This mode is, in fact, how all current commercial confocal laser scanning microscopes (CLSM) systems work. Minsky's invention remained largelly unnoticed, due most probably to the lack of intense light sources necessary for imaging and the computer horsepower required to handle large amounts of data. The great advances in computer, laser technology, and digital images acquisition have permitted to discover the application of the confocal microscope in a widely number of fields such as biology, geology or materials research. Laser light offers 
several advantages over other lights for confocal microscopy. Each kind of laser produces light of only one or a very few well defined wavelengths. The light is spatially and temporarily coherent. Spatially coherent light is light in which all the waves have the same frequency, direction, and polarization angle. Temporarily coherent light is light in which the waves have exactly the same phase and speed. This combination produces a beam of light that is bright and clearly focused. The high intensity of laser light is useful in getting a sufficiently bright spot of light onto the specimen, even when the specimen is dark.

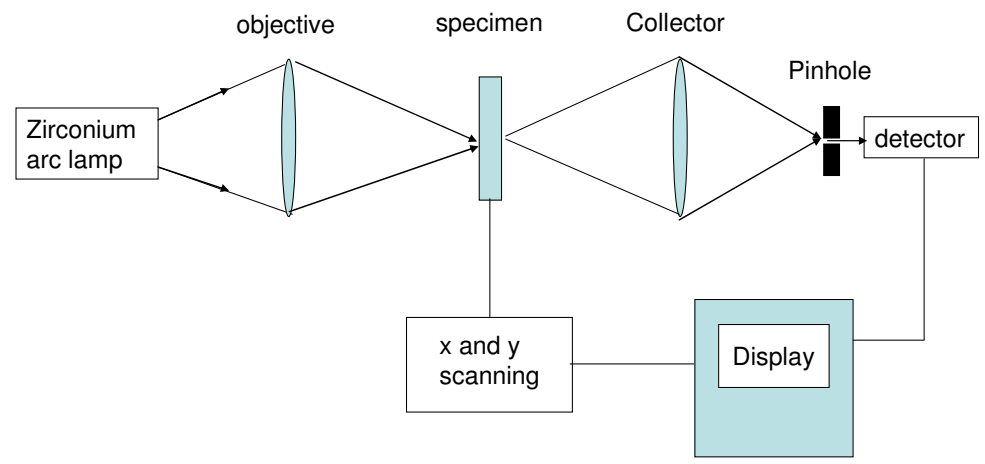

Fig. 1. Scheme of Minsky's invention, the first confocal microscope.

\subsection{Advantages of confocal microscopy over to conventional optical microscopy}

The main advantages of the confocal microscopy over the conventional optical microscopy can be summarised as follows:

a. Higher resolution. Resolution increases with the shorter wavelengths and is higher as the numerical aperture of the objective increases.

b. Better contrast. All undesirable light is neglected.

c. Possibility to obtain optical slices. By changing the pinhole aperture and the focal plane it is possible to obtain slices of different planes.

d. Three dimensions reconstruction. With the slices obtained in the different focal planes, it is possible to create a three dimensions image of the studied specimen.

\subsection{Kinds of confocal microscopy systems}

There are different kinds of confocal scanning techniques:

a. Single beam scanning, this system illuminates the specimen with only one light point and it is necessary to scan the specimen. There are two versions of this system: confocal stage scanning microscopy (CSSM) and confocal laser scanning microscopy (CLSM). The former the model designed by Minsky and uses a fixed laser beam, and the specimen is scanned using a motorized stage in the microscopy. The main characteristic of this system is the slow acquisition of images. Despite that, one of the advantages of this method is that the laser remains fixed and the aberrations due to the objective are lower, the optical response being constant during image acquisition. On the other hand, in confocal laser scanning microscopy the scan of the specimen is obtained by moving the laser beam. This movement is carried out using galvanometric mirrors that permit 
changing the incidence point on the specimen. Some of the advantages of this method are that the acquisition is faster than in the other system and the sample has not to be moved.

b. Multiple-beam scanning; in this system the microscope is equipped with a spinning disk containing an array of pinholes that allows scanning the specimen with multiple light beams at the same time. One of the advantages over single beam systems is the image acquisition speed. However, some disadvantages of this system are the low intensity of the images obtained and the thickness of the optical slice that is higher than in the CLSM systems.

\subsection{CLSM operation principles}

Fig. 2 illustrates the principal components and optical pathway in a confocal laser scanning microscope.

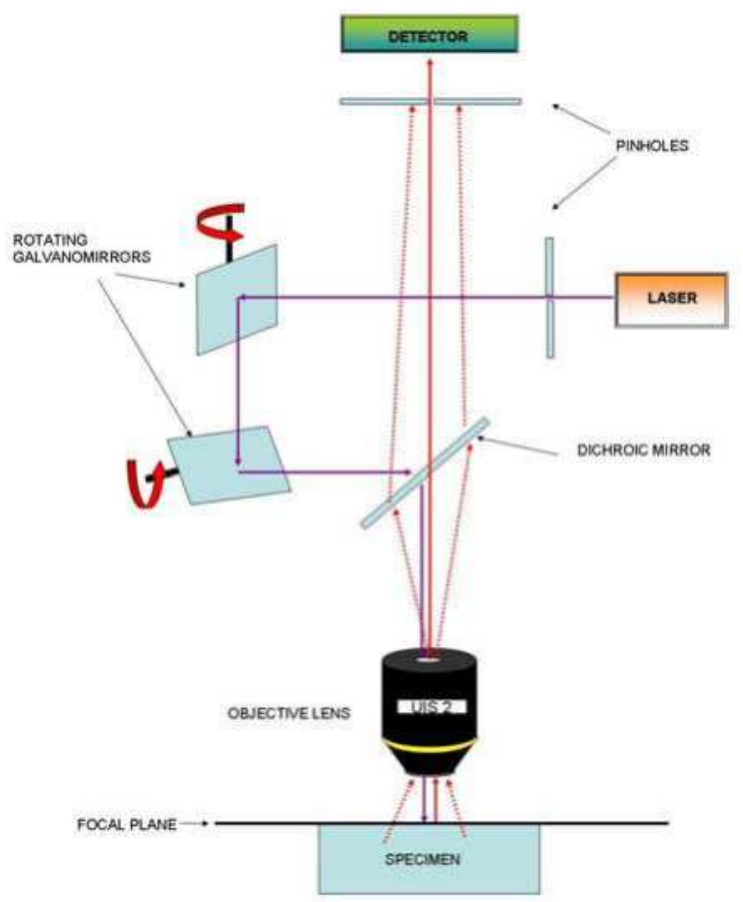

Fig. 2. Diagram of a confocal laser scanning microscope.

One or more lasers can be present in the CLSM systems. Some Kind of optical coupling mechanism such as optical fiber is used to allow the laser beam to enter the microscope system. Coherent light emitted by the laser system (excitation source) passes through a pinhole aperture that is situated in a conjugate plane (confocal) with a scanning point on the specimen and a second pinhole aperture positioned in front of the detector (a photomultiplier tube).Next, the laser beam is reflected by a set of scanning mirrors. These 
mirrors are mounted on a mechanism that can move them very precisely and very rapidly. One mirror scans the beam in the $\mathrm{X}$ direction, the other in the $\mathrm{Y}$ direction. Together, these mirrors scan the beam in a raster fashion. The beam is then reflected to the back focal plane of the objective lens. The objective lens focuses the beam onto the specimen. The result of all this is that a spot of light is scanned over a small area of the specimen. The size of this area is equal to or smaller than the objective lens's field of view. By changing the raster size it is possible to obtain higher magnifications with the same lens.

If the specimen is fluorescent or reflective, some fraction of light is reflected back to the objective lens. This light travels backwards along the same path as the laser did. This light then must pass through a semitransparent mirror or a dichroic mirror that reflects it away from the laser and towards the detection system. The first part of the detection system is the pinhole aperture. The aperture serves to allow only a small central portion of the reflected light to reach the light detectors. This light will pass through a polarizer that will only allow laser light with a different polarization angle from the initial laser light to pass through. The light enters a photomultiplier tube type detector and then the signal is transmitted to the computer where the image of the focal plane is generated.

\subsection{Main parameters of CLSM systems}

There are different parameters that are important in CLSM systems.

a. Laser wavelength and laser intensity. The lower the laser wavelength is, the greater the CLSM resolution is. Table 1 shows the different emission wavelengths of gas lasers use in CLSM. Higher intensities can be useful when the specimen is too dark and the light has to be reflected.

\begin{tabular}{|c|c|c|c|c|}
\hline \multirow{2}{*}{ Laser } & \multicolumn{4}{|c|}{ Wavelength (nm) } \\
\cline { 2 - 5 } & UV & Blue & Green & Red \\
\hline Helium-Cadmium & 325 & 442 & & \\
\hline Helium-Cadmium (RGB) & & 442 & $534 ; 538$ & 636 \\
\hline Low Power argon ion & & 488 & 514 & \\
\hline Water-cooled argon ion & $351 ; 364$ & $457 ; 488$ & $514 ; 528$ & \\
\hline Argon-Krypton mixed gas & & 488 & 568 & 647 \\
\hline Helium-neon (green) & & & 543 & \\
\hline Helium-neon (red) & & & & 633 \\
\hline
\end{tabular}

Table 1. Wavelengths of gas lasers used in CLSM.

b. Pinhole diameter. There is an optimal pinhole diameter for every lens. With this optimal pinhole the thickness of the slice is the lowest (maximum resolution in the $\mathrm{Z}$ axis). The thickness of the slices increases with the pinhole diameter.

c. Gain of the photomultiplier. With the gain, it is possible amplify the electrical signal generated by the photons detected in the photomultiplier. When the signal intensity is low, it can be improved by increasing the gain.

d. Scan rate of the laser. It is the number of lines per second that the laser scans. Resolution decreases at higher scan rates.

e. Image size. This parameter is defined as the number of pixels of the image. Resolution is improved with higher number of pixels. 


\section{The problem of corrosion}

\subsection{Importance of corrosion}

Corrosion is an important problem of metallic materials used in the technological, mechanical and structural applications and can cause failures and accidents. The importance of corrosion studies is threefold. First of all, economic point, as material losses due to the progressive deterioration or sudden break of metallic components such as pipes, tanks, devices, hulls, etc, would be lower Another point is the preservation of natural resources, the world's resources of metallic materials are limited. Furthermore, the manofacture of metallic components involves the use of energy and water. Last but not least important than is the issue of environmental and industrial safety. An inadequate maintenance of metallic components against the corrosion can be cause of accidents or leaks of dangerous products to the environment.

\subsection{Definition of corrosion}

According to the American Society for Testing and Materials, corrosion can be defined as "The chemical or electrochemical reaction between a material, usually a metal, and its environment that produces a deterioration of the material and its properties" (ASTM G-15 international, 1994). More in the scope of this research, in electrochemical corrosion the metallic surface is the site for two electrode reactions, which happen in different places, the anodic reaction and the cathodic reaction. The reactions can be written as follows:

$$
\begin{array}{cc}
\text { Anodic Reaction } & \mathrm{M} \rightarrow \mathrm{M}^{+\mathrm{n}}+\mathrm{ne} \\
\text { Cathodic Reaction } & \mathrm{Ox}+\mathrm{ne}^{-} \rightarrow \text { Red }
\end{array}
$$

Electrochemical corrosion takes place when the metallic materials are in contact with environments with electrolytic conductivity such as water, salt solutions or atmospheric humidity. Therefore, the presence of water molecules over the metallic surface is the necessary condition to produce electrochemical corrosion. The electrical contact between different metallic areas immersed in an electrolytic solution produces an electrical current due to the difference in potential between these areas. This electrical charge produces the movement of cathions and anions between cathodic and anodic areas. The metal surface that tends to solve (anodic area) is corroded in a process where the metallic atoms pass to the solution as positive ions leaving behind these electrons in the metal. On the other hand, the metal surface less prone to solve (cathodic area), remains immune to the corrosion attacks. This surface gains the electrons from the anodic area through the metallic mass, these electrons are supplied to an oxidant agent present in the electrolyte; this reaction is called reduction. The result of these electrochemical reactions is the deterioration of metals with the subsequent loss of the materials properties.

\subsection{Corrosion tests}

The measurement of the corrosion processes can be carried out by means of direct or indirect tests. The first one is a direct measure of the effect of the immersion of metals in an aggressive solution. One example of these tests is the weight-loss test, in this test the metal specimen is immersed in the solution under study under different conditions (temperature, time, concentration of aggressive anions, etc). Specimens are weighed before and after the 
test and the differences in weight are registered. The main disadvantage of this test is the long duration, sometimes months or years.

On the other hand, in the indirect measure tests, the electrical parameters (potential and current density) of the metallic specimens in the studied solutions are measured against a reference electrode. There are different indirect tests such as potentiodynamic curves, cyclic potentiodynamic curves, zero resistance ammeter test (ZRA), electrochemical impedance spectroscopy (EIS), etc. These tests are faster than the direct tests and provide very useful information about the corrosion processes.

\subsection{Forms of corrosion}

One of the main classifications of corrosion processes is related to attack morphology. As the location of the anodic and cathodic areas can vary, corrosion can be categorised as follows:

a. Uniform corrosion, the entire surface in contact with the electrolyte is attacked, and the loss of thickness and mechanical properties is similar in all the surface.

b. Pitting corrosion, occurs in localised surface areas, not greater than 1 or $2 \mathrm{~mm}^{2}$, and goes growing inside the material forming a cavity. Despite the fact that the quantity of affected material can be low, the problems can be very important.

c. Intergranular corrosion, occurs in the metals after heat treatment that produces the depletion of the alloying elements in the grain boundaries. It is an attack on the grain boundaries of a metal or alloy. The loss of mechanical properties is really important in this corrosion process.

d. Selective corrosion, the attack is not distributed in a homogeneous way on the surface. In this attack, one of the components of an alloy undergoes damage or transformation.

e. Galvanic corrosion, this kind of corrosion is related with the destruction of a metal that is in contact with a more noble metal, when they are in solutions that allow the flow of current.

f. Crevice corrosion is produced at the region of contact of metals with metals or non metals in crevices or junctions that are insufficiently aerated and the renovation of the corrosive media is difficult.

Differences in the attack morphology can be established by observation of the surface during or after the corrosion processes. Therefore, it is very important to have optical tools that permit the analysis of those differences. At this point it is when the CLSM techniques show that they can be very useful in the study of the corrosion processes.

\section{Previous corrosion studies with image acquisition systems}

In previous works of this research group, different electro-optical devices were employed in order to obtain images of the specimen surface during the electrochemical tests. The first electro-optical devices used were the patented devices P-200002525 and P-200002526 (García Antón et al., 2000a; García Antón et al., 2000b; García Antón et al., 2001; García Antón et al., 2003). These devices allow observing the electrode surface in real-time as it undergoes electrochemical corrosion. The experimental device consists of two elements: the electrochemical unit and the image acquisition section. The electrochemical system is composed of the data acquisition equipment, which registers the electrical signal obtained from the corrosion processes that take place inside a horizontal electrochemical cell. The image acquisition system consists of a microscope-stereoscope and a colour video camera assembled to the optical device. Fig. 3 shows a photograph of these devices. 


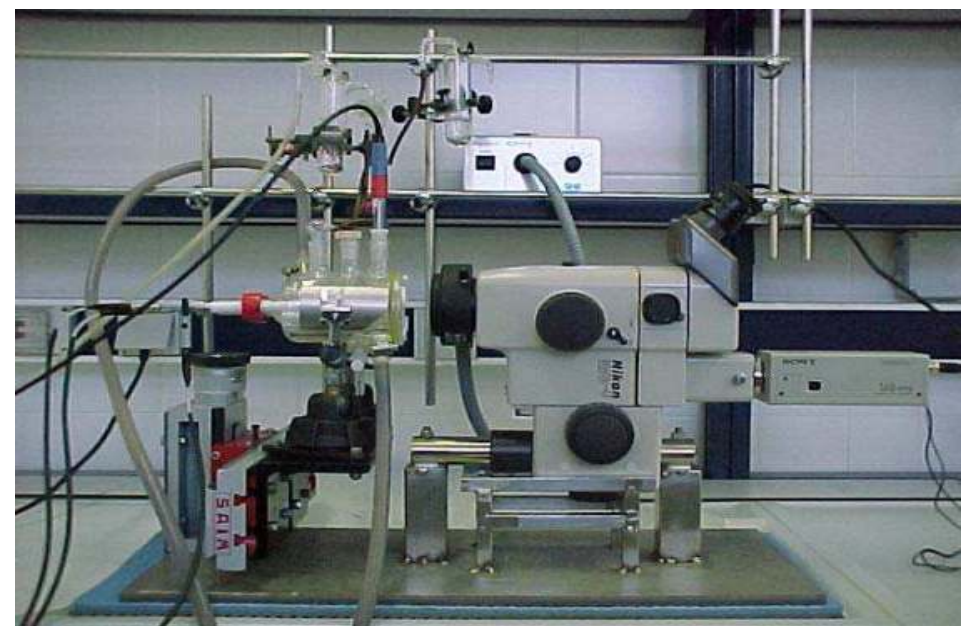

Fig. 3. Photograph of the patented electro-optical devices P-200002525 and P-200002526.

Some images obtained with these devices during potentiodynamic curves with copper (uniform corrosion) and duplex stainless steel (localised corrosion) are presented in Fig. 4. In these images, it is possible to distinguish between the generalised and localised processes. In the first one the entire surface of the copper is affected by the corrosion attack. In the case of stainless steel, corrosion begins at localised points.

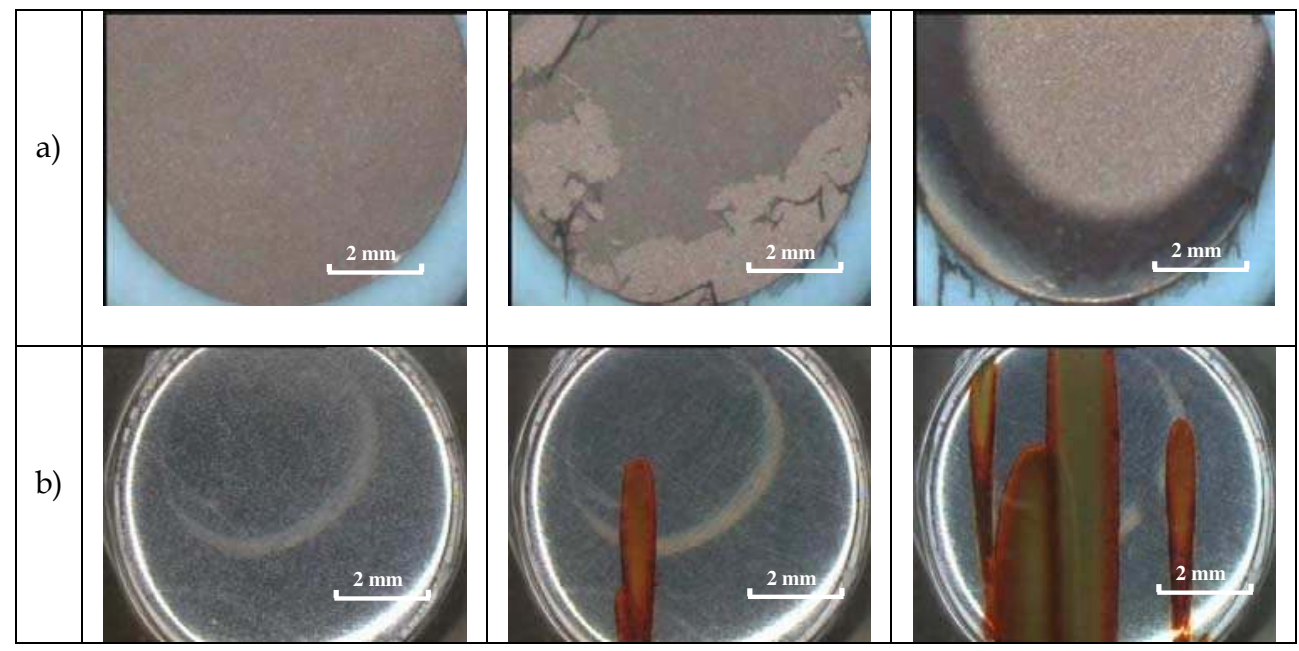

Fig. 4. Images of a) copper (generalised corrosion) and b) duplex stainless steel (localised corrosion) obtained with the electro-optical devices P-200002525 and P-200002526 during potentiodynamic curves in a $992 \mathrm{~g} / \mathrm{L} \mathrm{LiBr}$ solution at $25^{\circ} \mathrm{C}$.

An improvement of the previous electro-optical devices is the patented electrochemical cell P-200803389 (García-Antón et al., 2008). With this cell it is possible to visualise the specimens during the electrochemical tests and monitor the volume of gas generated in the 
cathode and the anode. In this way, reactions like hydrogen evolution (a very important reaction in the research of fuel cells) can be studied.

Some limitations of these electro-optical devices are the impossibility to obtain three dimensional images, the highest magnification is $75 x$, and the impossibility to correct slanted surfaces. Higher magnifications in the observation of corrosion processes is a very important point because despite the fact that the effects of corrosion processes are visible at large scale, its mechanisms happen at a smaller scale. Some authors have used microscopic systems such as microcells, scanning electrochemical microscopy or atomic force microscopy in order to study in-situ corrosion processes (García et al., 2008a; García et al., 2008b; Martin et al, 2008). These experimental devices can be applied to different settings, such as heterogeneous materials (dual phase steels, welding, etc).

\section{In-situ observation of corrosion processes}

\subsection{Description of the used CLSM}

The confocal laser scanning microscope is an "Olympus LEXT 3100 OLS" with the following features:

a. The wavelength of the laser is $408 \mathrm{~nm}$ (Violet Laser Diode).

b. The horizontal resolution is $0.22 \mu \mathrm{m}$ and the vertical resolution is $0.01 \mu \mathrm{m}$.

c. Three acquisition modes: optical light, non confocal laser, and confocal laser.

d. A motorized stage that permits moving quickly to the region of interest.

e. The change of the objective lens is executed electrically through PC control.

$\mathrm{f}$. The raster of the laser scan can be reduced up to an additional magnification of $14 \mathrm{x}$ without need for changing the lens.

\subsection{In-situ study of heat treatments}

When stainless steels are heated improperly, they can undergo morphological changes that affect their corrosion resistance. During heat treatments new phases can appear or chromium carbides can precipitate at the grain boundaries. These processes deplete the alloying elements in certain areas that lose their corrosion resistance. This phenomenon is called sensitisation to intergranular corrosion. This kind of corrosion causes serious problems because it can propagate along a metal component without visible damage. Therefore, the loss of mechanical properties can occur without apparent signs, causing an accident.

Fig. 5 shows two images obtained by scanning electron microscopy (SEM) of a duplex stainless steel (DSS), Alloy 900, before and after heat treatment at $825^{\circ} \mathrm{C}$ in an inert atmosphere for 1 hour (Leiva-García et al., 2009). In this image it can be observed how after heat treatment new phases appear and the percentage of one of the initial phases (ferrite) decreases. Duplex stainless steels are widely used in oil, chemical, petrochemical, nuclear, and marine industries. Duplex stainless steels have a two-phase microstructure, in which ferrite and austenite are present in relatively large separate quantities and in approximately equal volume fractions. Therefore, one important application of the CLSM to corrosion studies is the in-situ observation of metal evolution during heat treatment in order to associate the morphological changes due to heating with the further corrosion behaviour of the metal.

A "Limkam" heating stage can be accommodated in the CLSM stage in order to observe the metal evolution during heat treatment. The sample is placed inside the ceramic sample cup so that it is heated from underneath as well as from the sides; a ceramic heat shield is placed over the top to prevent heat from escaping this micro oven. The stage body and large 


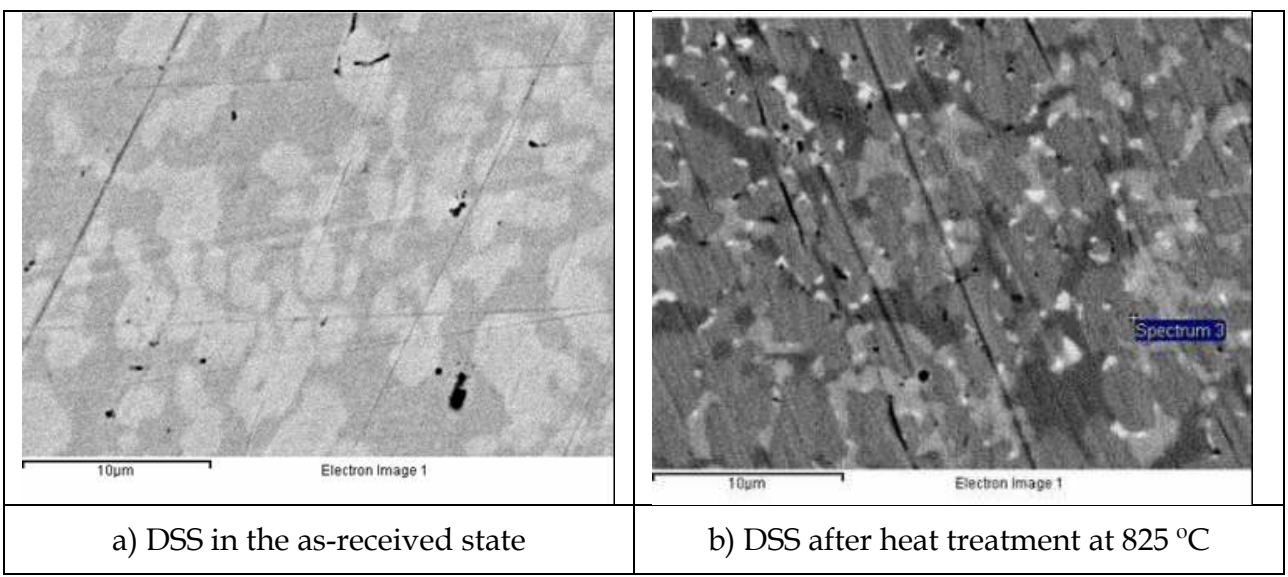

Fig. 5. Backscattered electron images obtained by SEM of a DSS in the unsensitised and sensitised state.

diameter quartz lid window are kept at a safe temperature by sealed circulating water. Furthermore, there is a gas-tight chamber for atmospheric control that allows carrying out heat treatments in an inert atmosphere. The maximum temperature that can be reached is $1500{ }^{\circ} \mathrm{C}$, close to the melting point of different stainless steels.

Prior to heat treatment, the specimen was wet abraded from 220 Silicon Carbide (SiC) grit to a $4000 \mathrm{SiC}$ grit finish, polished with 1 micron alumina and finally rinsed with distilled water. Then, the specimen was put in the crucible and the stage was closed in order to maintain an inert atmosphere. Prior to heating, an argon flow passed through the heating stage in order to purge the oxygen; during the test this argon atmosphere was maintained. After that a heating ramp was programmed from $25^{\circ} \mathrm{C}$ to $825^{\circ} \mathrm{C}$ and the temperature was held for 1 hour. Different images in 2 and 3 dimensions were obtained during this process. Fig. 6 shows 2-D images of the DSS surface during one of these heat treatments obtained by means of the confocal laser scan. These images are the reconstruction of the different slices obtained during image acquisition. The evolution of the DSS surface can be analysed from the photographs of Fig 6., during the heating ramp two phases are clearly visible (Fig 6. a)), the main difference being the expansion coefficient that produces different height evolution in the phases during heating. These differences in topography can be detected with the CLSM and this differentiation is higher as greater the resolution is. According to the literature there is a temperature interval $\left(600{ }^{\circ} \mathrm{C}-1050{ }^{\circ} \mathrm{C}\right)$ where many carbides, nitrides, intermetallic, and secondary phases can precipitate (Martins M. and Casteletti L.C., 2005; Pohl M. et al., 2007). Fig. 6 b), c), and d) show how these changes affect the specimen's surface. On the other hand, during heating at $825^{\circ} \mathrm{C}$ (Fig. 6 e) and f)) the volume of the dark areas grows and this change is registered by the CLSM. These areas could be related with accumulations of the alloying elements. Fig. 7 presents a 3-D image of the specimen at the end of the heat treatment.

After heat treatment, electrochemical tests can be carried out in order to relate the electrochemical behaviour with the morphological changes that happen as a consequence of heating. 


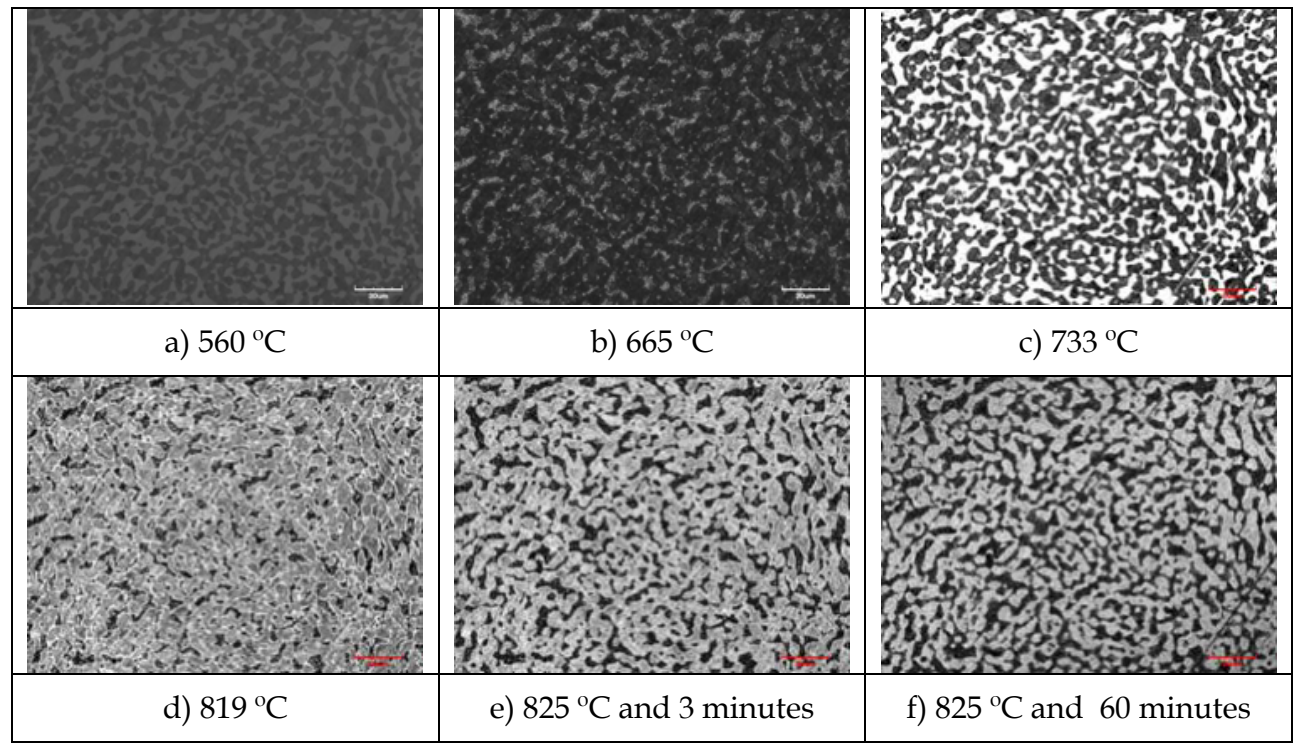

Fig. 6. 2-D images of a DSS specimen during heat treatment in an argon inert atmosphere at $825^{\circ} \mathrm{C}$ for 1 hour.

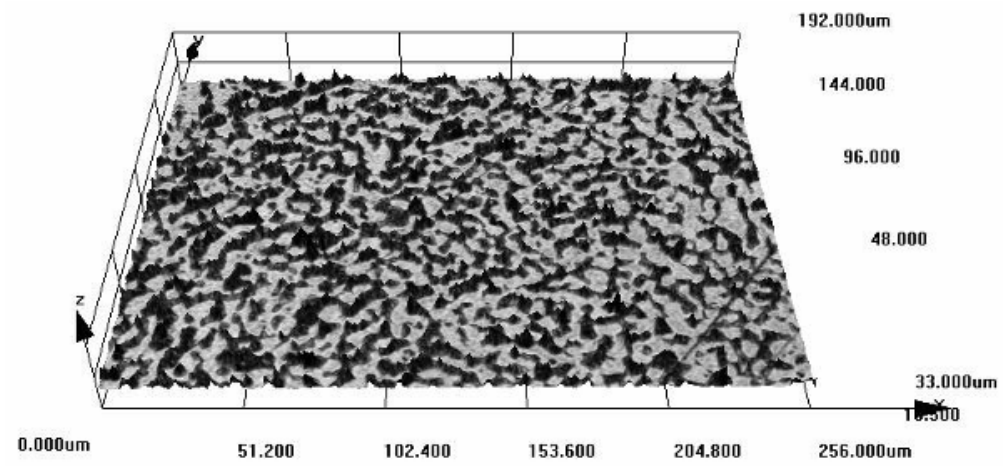

Fig. 7. A 3-D image of a DSS specimen during the last minute of a heat treatment in an argon inert atmosphere at $825^{\circ} \mathrm{C}$ during 1 hour.

Another application of the heating stage could be the study of dry corrosion. Dry corrosion is defined as the corrosion that happens at high temperatures when the metal is in contact with vapour or gases. If the inert atmosphere is replaced by air or an oxygenated atmosphere, the growth of the oxide film with temperature and time could be studied by means of the CLSM.

\subsection{In-situ study of corrosion attacks}

A device called potentiostat was employed in the electrochemical tests. This electronic device provides a constant or variable potential with regard to a reference electrode. The 
counter electrode is used to close the electric circuit. This electrode is normally made of materials resistant to corrosion attacks in the medium studied (gold, platinum...). While the potential is imposed to the metallic specimen, the current density is registered. Another work option with the potentiostat is the galvanostatic mode. In this case a constant or variable current density is imposed and the potential variations are registered.

A minicell that can be placed in the CLSM stage was designed in order to observe corrosion attacks during the electrochemical tests (Leiva-García et al., 2010). The minicell permits using confocal laser scanning microscopy to observe the beginning of the microscopic corrosion process during the tests. Fig. 8 shows a scheme of the minicell. The cell is made of glass and consists of two parts. The first part is a base to support the specimens. This base has four small supports to maintain the specimen in a horizontal position (Fig. 8 c)), and a frosted lateral surface to close the cell with the upper part. The upper part has the inlets and outlets of the cell. There are two inlets for the electrodes, the first of them is for the reference electrode, which is a silver-silver chloride with $3 \mathrm{M} \mathrm{KCl}$ reference mini-electrode. The second inlet serves to take out the electrical connection of the specimen. The counter electrode consists of two platinum filaments that pass through the glass and are connected outside the cell to the potentiostat. When the cell is closed, it is under a completely insulated atmosphere. Additionally, an inlet and an outlet serve to introduce the electrolyte into the cell from a glass container by means of a pump. The glass container has a thermostatic jacket that controls the temperature of the solution. It is also possible to bubble nitrogen in the solution to deaerate it. Fig. 9 shows two photographs of the cell in the CLSM stage.

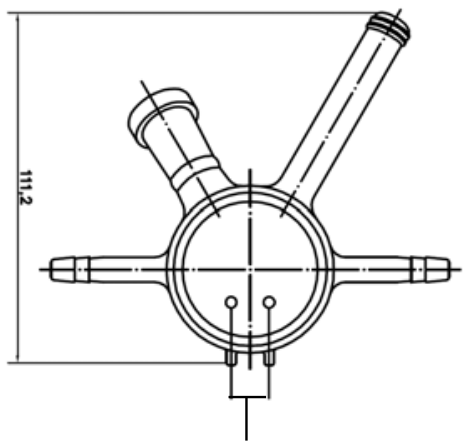

(a)

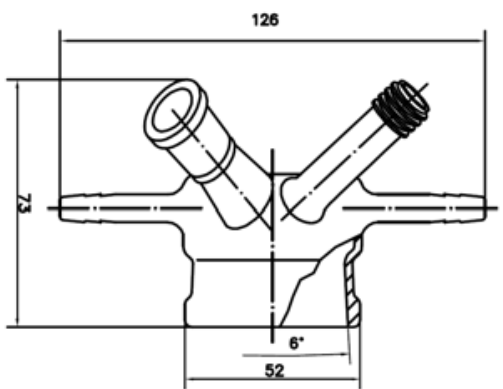

(b)

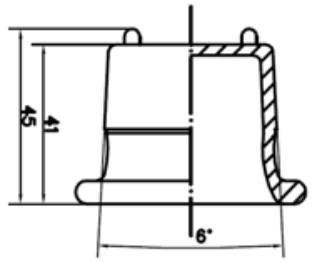

(c)

Fig. 8. Scheme of the parts of the minicell: (a) Main view of the top of the cell, (b) Cross view of the top of the cell, and (c) Cross view of the base of the cell. (Measurements have been made in millimetres). 


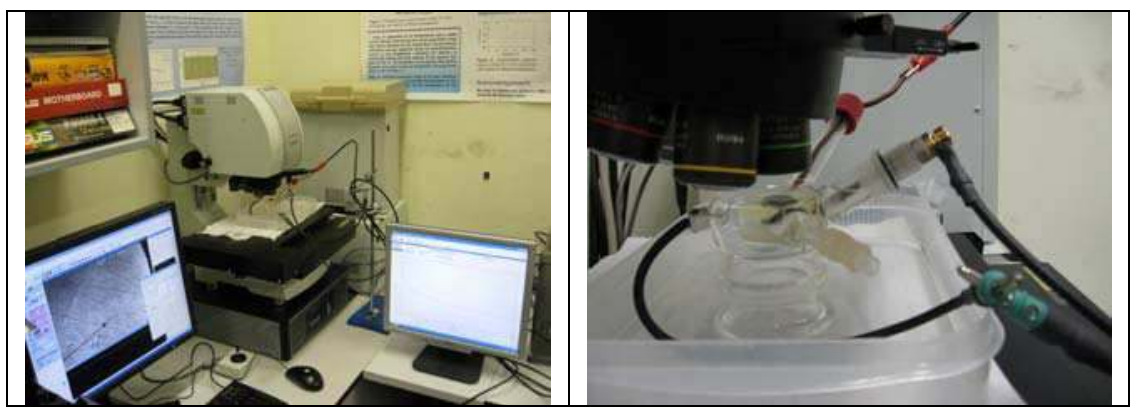

Fig. 9. Photographs of the minicell placed in the CLSM.

The material used in the minicell's tests was a duplex stainless steel, Alloy 900 (UNS 1.4462). The specimens were machined as shown in Fig. 10. These electrodes have a hole drilled on the base, where the electrical connection was made, and a cylindrically reduced rod $1.6 \mathrm{~mm}$ in diameter. The electrode was covered with an epoxy-resin; in this way only a circular area $1.6 \mathrm{~mm}$ in diameter was exposed to the corrosive solution. The electrical connection to the potentiostat was done by means of a conductor wire. Prior to the electrochemical tests, the specimens were wet abraded from 220 Silicon Carbide (SiC) grit to a $4000 \mathrm{SiC}$ grit finish, and finally rinsed with distilled water.

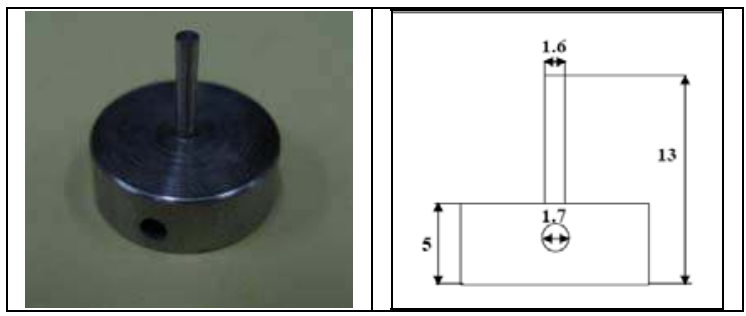

Fig. 10. Machined working electrode (measurements in millimetres).

Galvanodynamic curves were conducted in aqueous $992 \mathrm{~g} / \mathrm{L} \mathrm{LiBr}$ solutions at $25{ }^{\circ} \mathrm{C}$ in order to check the morphology of the attack with the CLSM. These tests allow controlling the current, and therefore, it is possible to control the corrosion rate when the damage begins. This issue is important because one of the objectives of the work is the study of the morphology of the first stages and propagation of corrosion; thus, it is very important to control the speed of the process. The $\mathrm{H}_{2} \mathrm{O}-\mathrm{LiBr}$ solution was selected because is the most commonly employed refrigerant/absorbent couple in absorption systems due to their favourable thermophysical properties. However, $\mathrm{LiBr}$ can cause serious corrosion problems on metallic components in refrigeration systems.

The $992 \mathrm{~g} / \mathrm{L} \mathrm{LiBr}$ aqueous solution was deaerated by bubbling nitrogen for 15 minutes, prior to immersion. Before each test, the specimen was immersed in the test solution for 1 hour at the open circuit potential (OCP). After the OCP test, the specimen's current density was reduced to $0 \mathrm{~mA} / \mathrm{cm}^{2}$ during 60 seconds so as to begin all the tests under the same conditions. Then, the galvanodynamic curves were recorded from $0 \mathrm{~mA} / \mathrm{cm}^{2}$ to positive current densities at a $10^{-5} \mathrm{~mA} / \mathrm{s}$ sweep rate. Images of the surface of the working electrode were obtained during the tests with the CLSM. During the OCP an image of the tested 
specimen was obtained with the 200x objective. The field observed with the $200 x$ objective is smaller than that of the specimen. Therefore, it is necessary to take different confocal images and later reconstruct the entire area of the specimen. Fig. 11 shows an example of a specimen surface during OCP.

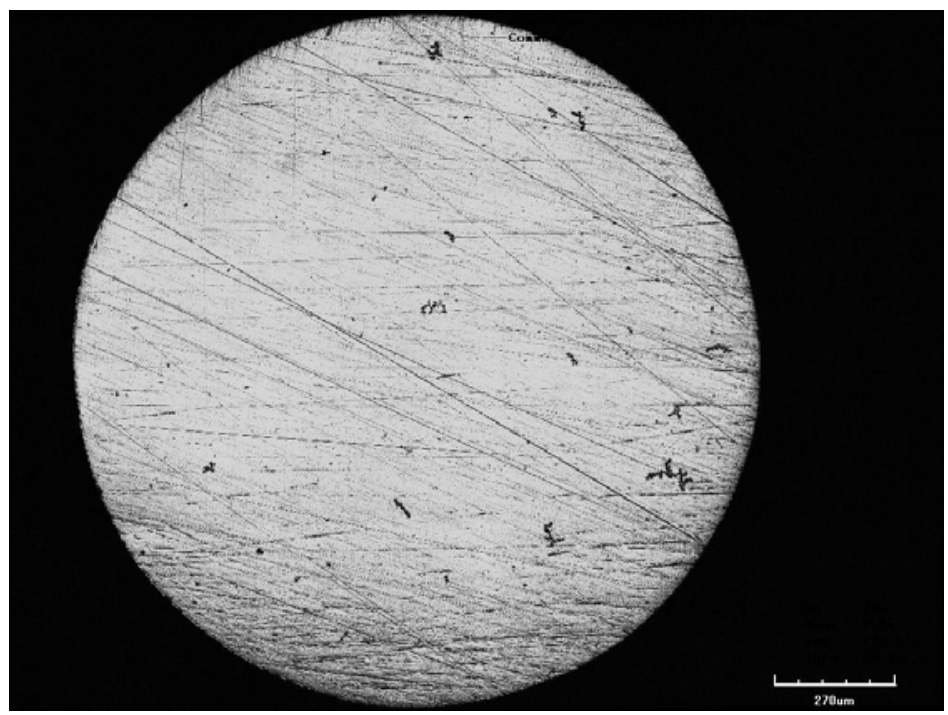

Fig. 11. Laser confocal image of the Alloy 900 specimen during OCP test in the LiBr solution. The image is a tiling reconstruction of different fields obtained with the 200x objective.

Fig. 12 shows different steps of the corrosion evolution during a galvanodynamic test. In these images, it can be observed how the corrosion process spreads inside the cloud of corrosion product and affects first one of the phases and then the other phase. When the cloud of corrosion product grows, it catalyses the corrosion in the new occupied area. According to some authors (Dornhege M. et al., 2007; Wu B. et al., 1997), the release of aggressive anions from pits and the subsequent diffusion of corrosion product over the electrode surface causes weakening of the protective passive film and each active pit is more likely to generate further pits in its surrounding.

The area of the corrosion expansion was calculated by image analysis as the projected area of the image. It was observed that the larger the damaged area, the lower the effective current density. The effective current density is related to the damage area, this area is the anodic area (where the dissolution of the metal happens) and the entire current of the test has to pass through this area. Fig. 13 shows the evolution of the damaged area and the effective current density during a galvanodynamic test. At the beginning of pit formation the effective current density is very high, and it is at this point when the passive film is broken. This is in accordance with the literature (Szklarska-Smialowska, 2002), because the breakdown of the passive film should be accompanied by a very high local current density. Therefore, the beginning of the corrosion processes is very fast and the damaged area grows quickly during the first stages of the attack. In addition, the damaged area (anodic area) / unaffected area (cathodic area) ratio is very unfavourable for the pit. The greater the damaged area, the more slowly the corrosion product spreads over a new unaffected area. 


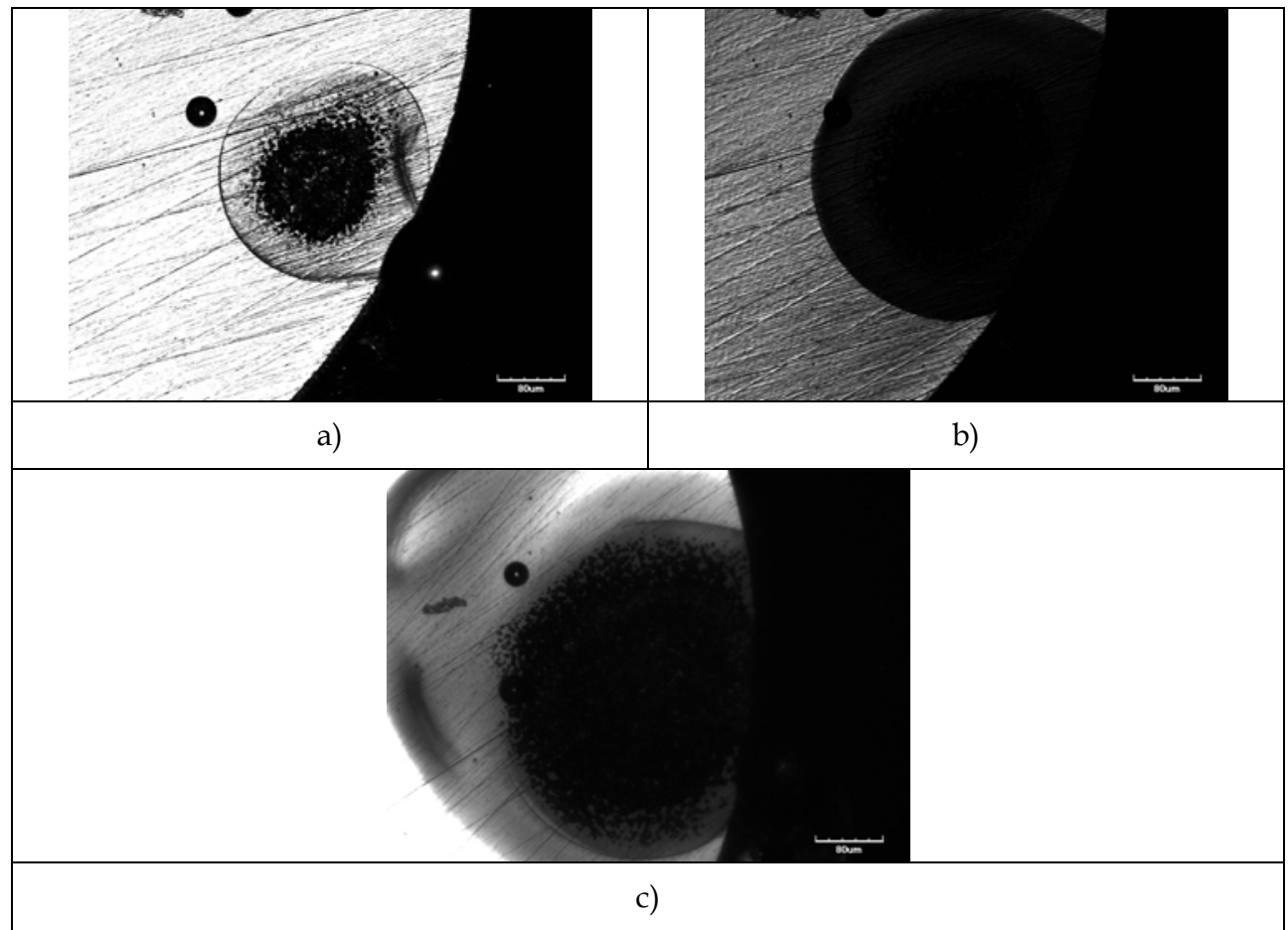

Fig. 12. Laser non-confocal images of the Alloy 900 specimen at different points of a galvanodynamic test in the $\mathrm{LiBr}$ solution at $25^{\circ} \mathrm{C}$.

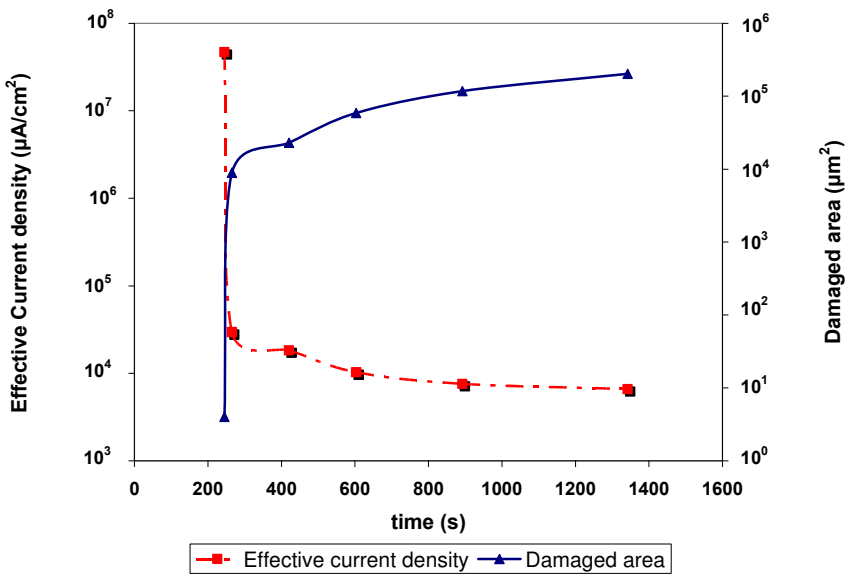

Fig. 13. Effective current density and evolution of the damage area during a galvanodynamic test in the $992 \mathrm{~g} / \mathrm{L} \mathrm{LiBr}$ solution at $25^{\circ} \mathrm{C}$. 
The reason to consider the projected area as the effective area is the difficulty to measure online the real area during the tests, because there is a cloud of corrosion product over the affected pit. This point could be a drawback of the technique. However, this technique offers the possibility to detect the cloud of corrosion product with the CLSM because its different optical properties can offer additional information about corrosion processes. The volume of these clouds of corrosion product can be measured and related with the electrochemical signal. Fig. 14 shows three different images of the growth of the cloud of corrosion product during a galvanodynamic test in the $992 \mathrm{~g} / \mathrm{L} \mathrm{LiBr}$ solution at $25^{\circ} \mathrm{C}$.

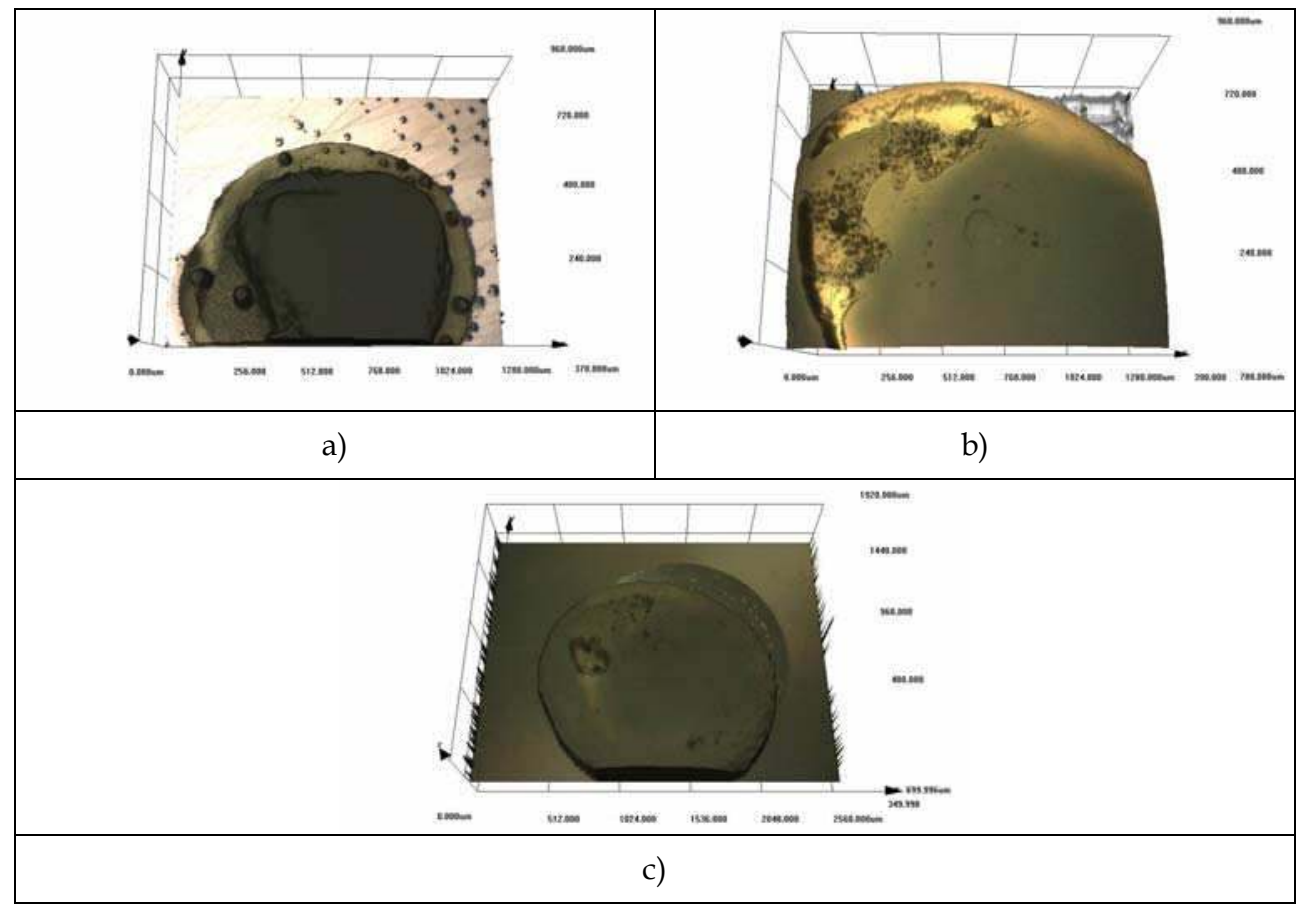

Fig. 14. 3-D colour images of the corrosion product over Alloy 900 during the galvanodynamic curve in $992 \mathrm{~g} / \mathrm{L} \mathrm{LiBr}$ solution at $25^{\circ} \mathrm{C}$.

\section{Ex-situ visualization of corrosion effects}

The evaluation of the specimens after the tests is an important part of the corrosion studies in order to analyse the morphology of the attack and to obtain metrological data of the damage. Confocal microscopy offers some advantages over conventional optical microscopy: correction of slanted surfaces, higher resolution, 3-D image generation, etc. Two applications of CLSM to ex-situ corrosion studies are presented below.

\subsection{Ex-situ study of sensitised and unsensitised specimens}

Fig. 15 shows two images of a highly alloyed austenitic stainless steel (Alloy 926) after a galvanodynamic curve in the $992 \mathrm{~g} / \mathrm{L} \mathrm{LiBr}$ solution at $25^{\circ} \mathrm{C}$. The first one corresponds to the 
alloy in the as-received state and the second one is the same alloy after heat treatment at $825^{\circ} \mathrm{C}$ for 1 hour in an inert atmosphere.

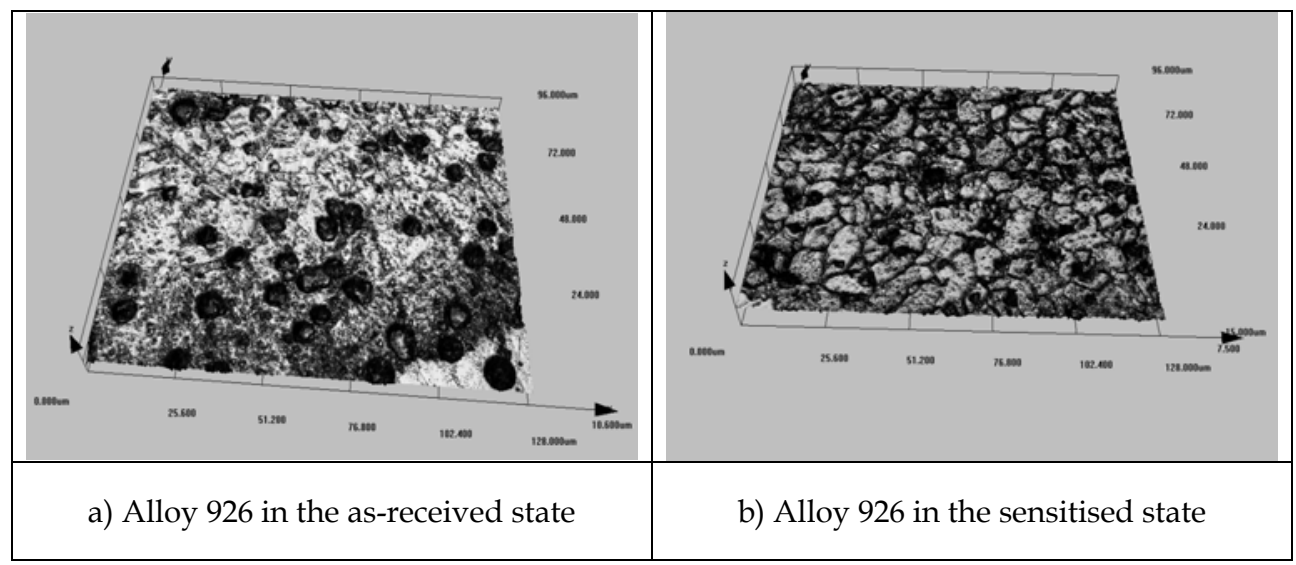

Fig. 15. 3-D images in laser intensity of a highly alloyed austenitic stainless steel (Alloy 926) after a galvanodynamic curve in the $992 \mathrm{~g} / \mathrm{L} \mathrm{LiBr}$ solution at $25^{\circ} \mathrm{C}$.

The less corrosion resistant areas are those first attacked during the galvanodynamic tests. In the case of Alloy 926 in the as-received state, the formation of pits during corrosion spread is a random process because the probability of attack is the same in the entire surface. On the other hand in the sensitised Alloy 926, the attack grows along the grain boundaries. This kind of attack is due to the chromium carbide precipitation during heat treatment. These carbides deplete the alloying elements in the surrounding area, which are less corrosion resistant than the rest of the surface.

\subsection{Ex-situ study of specimens under cavitation tests}

In a recent work of this research group (Fernández-Domene et al., 2010), the regeneration of the passive film (protective oxide layer formed over stainless steels) after mechanical damage was studied. The passive film breakdown was produced by cavitation and the damage generated on the alloy surface was quantified by means of image analysis and CLSM. Fig. 16 shows an image of a pit in Alloy 31 (highly alloyed stainless steel) under cavitation conditions in a $992 \mathrm{~g} / \mathrm{L} \mathrm{LiBr}$ solution at $25^{\circ} \mathrm{C}$. From the analysis of the images obtained with CLSM we can conclude that:

a. The attack morphology was different depending on the conditions. Under static conditions, the morphology of the damage generated on the electrode surface was uniform (although the initial mechanism was pitting corrosion). However, under cavitation conditions, the attack was localized and visible pits appeared on the surface.

b. Damage quantification on the Alloy 31 surface in $992 \mathrm{~g} / \mathrm{L} \mathrm{LiBr}$ solution during the potentiostatic tests, by cavitation- corrosion using Confocal Laser Scanning Microscopy and image analysis techniques showed that the volume, surface area and depth of these damages increased with increasing potentials. Moreover, a linear relationship between the damaged area and the applied potential was obtained. 


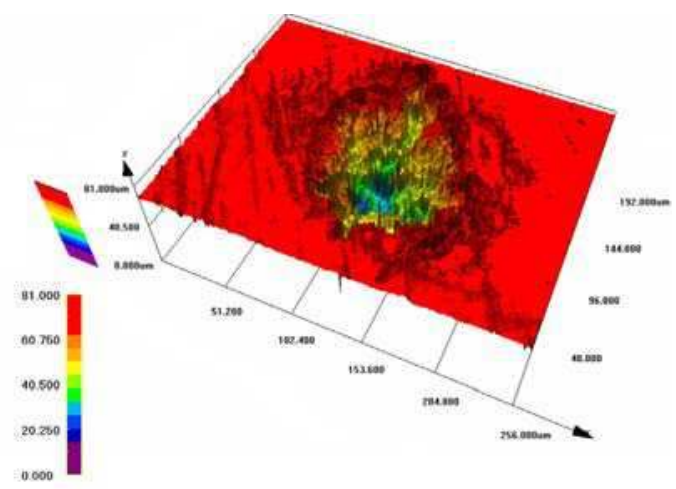

Fig. 16. 3-D Image of an Alloy 31 pit in $992 \mathrm{~g} / \mathrm{L} \mathrm{LiBr}$ solution, under cavitation conditions.

\section{Conclusions}

An important issue in corrosion studies is the analysis of attack morphology. CLSM presents different advantages over optical microscopy (higher horizontal and vertical resolution, 3-D reconstruction, correction of slanted surfaces...). Different applications of CLSM to corrosion research have been presented in this chapter. CLSM is a valuable technique for a better understanding of corrosion processes. The analysis of the in-situ processes has allowed us to observe morphological changes during heat treatments; these changes can be associated with further SEM analysis or electrochemical behaviour during corrosion tests. On the other hand, the electrochemical tests carried out using the minicell and CLSM help to observe in-situ the beginning and evolution of corrosion during electrochemical tests at high magnifications. Different metrological parameters like damage area or volume of the cloud of corrosion product can be obtained. Furthermore, the examination of the specimens after corrosion tests provides very useful and precise information about the morphology of the attack and its dimensions. Therefore, CLSM has demonstrated to be a powerful tool in the corrosion research.

\section{Acknowledgements}

We wish to express our gratitude to MEC (CTQ2009-07518), to FEDER, to the Generalitat Valenciana for its help in the CLSM acquisition (MY08/ISIRM/S/100) and to Dr. Asunción Jaime for her translation assistance

\section{References}

ASTM international (1994). ASTM G15-94 Standard Terminology Relating to Corrosion and Corrosion Testing. American Society for Testing Materials (1994), USA.

Dornhege M., Punckt C., Hudson J.L., \& Rotermund HH. (2007). Spreading of corrosion on stainless steel. Simultaneous Observation of metastable pits and oxide film. Journal of the electrochemical society, 154, (november, 2007) C24-C27, ISSN 0013-4651.

Fernández-Domene R.M., Blasco Tamarit M.E., Garcia-Garcia D.M., \& Garcia-Anton J (2010). Repassivation of the damage generated by cavitation on UNS N08031 in a LiBr 
solution by means of electrochemical techniques and Confocal Laser Scanning Microscopy. Corrosion science, 52, 10, (October, 2010), 3453-3464, ISSN 0010-938X.

García Anton J., Igual Muñoz A., Guiñón J.L., \& Pérez Herranz V. (2000a). Electro-Optical Method by On-line Visualization of Electrochemical Process and Experimental Process. Spain P-200002525 . 2000a.

García Anton J., Igual Muñoz A., Guiñón J.L. \& Pérez Herranz V. (2000b). Horizontal Electrochemical Cell by the Electro-Optical Analysis of Electrochemical Process. Spain P-200002526. 2000b.

García Anton J., Igual Muñoz A., Guiñón J.L. \& Pérez Herranz V. (2001). A new technique for online visualization of the electrode surface under electrochemical corrosion processes. Journal of Applied electrochemistry, 31, 11, (November, 2001). 1195-1202, ISSN 0021-891X.

García Anton J., Igual Muñoz A., Guiñón J.L., Pérez Herranz V., \& Pertusa-Grau J. (2003). Online visualization of corrosion processes of zinc and a $\mathrm{Cu} / \mathrm{Zn}$ galvanic pair in LiBr solutions. Corrosion, 59, 2, (February, 2003), 172-180, ISSN 0010-9312.

García, C., de Tiedra M.P., Blanco Y., Martin O., \& Martin F. (2008a). Intergranular corrosion of welded joints of austenitic stainless steels studied by using an electrochemical minicell. Corrosion Science, 50, 8, (August, 2008) 2390-2397, ISSN 0010-938X .

García, C., Martin F., de Tiedra P., Blanco Y., \& Lopez M. (2008b). Pitting corrosion of welded joints of austenitic stainless steels studied by using an electrochemical minicell. Corrosion Science, 50, 4, (April, 2008) 1184-1194, ISSN 0010-938X.

Garcia-Antón J., Blasco Tamarit M.E., Garcia-Garcia D.M., Guiñón-Pina V., Leiva-Garcia R., \& Pérez-Herranz V. (2008). Celda electroquímica de generación de gases para el análisis de procesos electroquímicos. (Spain) P-2000803389 . 2008.

Leiva-García R., Muñoz-Portero M.J., \& García-Antón J. (2009). Evaluation of Alloy 146, 279, 900 and 926 sensitization to intergranular corrosion by means of electrochemical methods and image analysis. Corrosion Science, 51, 9, (September, 2009) 2080-2091, ISSN 0010-938X.

Leiva-García, R., García-Antón J., \& Muñoz-Portero, M.J. (2010). Contribution to the elucidation of corrosion initiation through confocal laser scanning microscopy (CLSM). Corrosion Science 52, 6, (June, 2010) 2133-2142, ISSN 0010-938X.

Martin, F. A., C. Bataillon \& J. Cousty. (2008). In situ AFM detection of pit onset location on a 304L stainless steel. Corrosion Science, 50, 1, (January, 2008) 84-92, ISSN 0010-938X.

Martins M. \& Casteletti L.C. (2005). Heat Treatment Temperature Influence on ASTM A890 GR 6A Super Duplex stainless Steel Microstructure. Materials characterization 55, 3, (September, 2005) 225-233, ISSN 1044-5803.

Minsky, M. U.S. Patent No. 3013467. 1957.

Minsky, M. (1988). Memoir on inventing the confocal microscope. Scanning 10 (November, 1988), 128-138.

Pohl M., Storz O., \& Glogowski T. (2007) Effect of intermetallics precipitations on the properties of duplex stainless steel. Materials characterization 58, 1, (January, 2007) 65-71 ISSN 1044-5803.

Szklarska-Smialowska Z. (2002). Mechanism of pit nucleation by electrical breakdown of the passive film. Corrosion Science, 44, 5, (May, 2002) 1143-1149, ISSN 0010-938X.

Wu B., Scully J.R., Hudson J.L., \& Mikhailov A.S. (1997) Cooperative Stochastic Behavior in Localized Corrosion. Journal of the electrochemical society 144, 5, (May, 1997) 1614 1620, ISSN 0013-4651. 


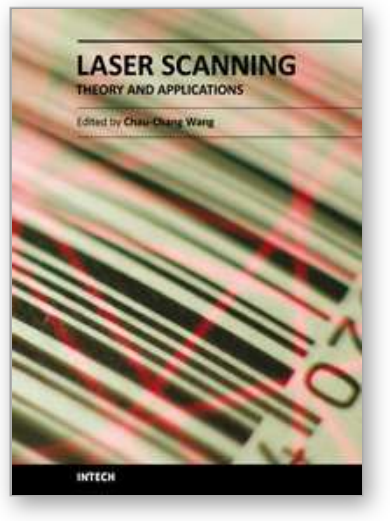

\author{
Laser Scanning, Theory and Applications \\ Edited by Prof. Chau-Chang Wang
}

ISBN 978-953-307-205-0

Hard cover, 566 pages

Publisher InTech

Published online 26, April, 2011

Published in print edition April, 2011

Ever since the invention of laser by Schawlow and Townes in 1958, various innovative ideas of laser-based applications emerge very year. At the same time, scientists and engineers keep on improving laser's power density, size, and cost which patch up the gap between theories and implementations. More importantly, our everyday life is changed and influenced by lasers even though we may not be fully aware of its existence. For example, it is there in cross-continent phone calls, price tag scanning in supermarkets, pointers in the classrooms, printers in the offices, accurate metal cutting in machine shops, etc. In this volume, we focus the recent developments related to laser scanning, a very powerful technique used in features detection and measurement. We invited researchers who do fundamental works in laser scanning theories or apply the principles of laser scanning to tackle problems encountered in medicine, geodesic survey, biology and archaeology. Twenty-eight chapters contributed by authors around the world to constitute this comprehensive book.

\title{
How to reference
}

In order to correctly reference this scholarly work, feel free to copy and paste the following:

Rafael Leiva-García, José García-Antón and Ma José Muñoz-Portero (2011). Application of Confocal Laser Scanning Microscopy to the In-situ and Ex-situ Study of Corrosion Processes, Laser Scanning, Theory and Applications, Prof. Chau-Chang Wang (Ed.), ISBN: 978-953-307-205-0, InTech, Available from: http://www.intechopen.com/books/laser-scanning-theory-and-applications/application-of-confocal-laserscanning-microscopy-to-the-in-situ-and-ex-situ-study-of-corrosion-proc

\section{INTECH}

open science | open minds

\section{InTech Europe}

University Campus STeP Ri

Slavka Krautzeka 83/A

51000 Rijeka, Croatia

Phone: +385 (51) 770447

Fax: +385 (51) 686166

www.intechopen.com

\section{InTech China}

Unit 405, Office Block, Hotel Equatorial Shanghai

No.65, Yan An Road (West), Shanghai, 200040, China 中国上海市延安西路65号上海国际贵都大饭店办公楼 405 单元

Phone: +86-21-62489820

Fax: $+86-21-62489821$ 
(C) 2011 The Author(s). Licensee IntechOpen. This chapter is distributed under the terms of the Creative Commons Attribution-NonCommercialShareAlike-3.0 License, which permits use, distribution and reproduction for non-commercial purposes, provided the original is properly cited and derivative works building on this content are distributed under the same license. 